\title{
DE SÃO PAULO A PARIS: o jovem Michael Löwy entre socialismo e sociologia
}

\author{
Fabio Mascaro Querido*
}

\begin{abstract}
Mais conhecido por sua afortunada trajetória internacional, em especial por aquela que se inicia a partir do final dos anos 1960 na França, Michael Löwy deu os primeiros passos de seu itinerário intelectual em São Paulo, na segunda metade da década de 1950, época em que cursou a graduação em Ciências Sociais na Faculdade de Filosofia da USP, então localizada na Rua Maria Antônia. O objetivo deste artigo é exatamente analisar a importância desse processo de formação intelectual de Löwy, entre o final da década de 1950 e meados da de 1970. Busca-se analisar algumas das linhas de força desse momento da trajetória intelectual do autor, das suas primeiras pesquisas sobre o movimento operário no âmbito da sociologia paulista até seus trabalhos mais teóricos - realizados na França - sobre as obras de Marx, Lukács e outros "intelectuais revolucionários".
\end{abstract}

PALAVRas-CHAvE: Intelectuais. Sociologia. Socialismo. Cosmopolitismo. Engajamento.

\section{ENTRE POLÍTICA (SOCIALISTA) E CIÊNCIA (SOCIOLÓGICA)}

Michael Löwy é bastante conhecido por sua exitosa carreira intelectual internacional, especialmente impulsionada desde que se instalou em definitivo na França, no final dos anos 1960. Bem menos notório, porém, embora de importância decisiva, é o período em que, ainda vivendo em São Paulo, participou como estudante - de um momento fundamental da consolidação institucional da sociologia em São Paulo, na USP, então localizada na Rua Maria Antônia, na segunda metade da década de 1950. Aluno de Florestan Fernandes, Fernando Henrique Cardoso, Octávio Ianni, Azis Simão, dentre outros, o jovem socialista militante participou como estudante convidado do hoje mitificado "Seminário d'O Capital" nos últimos anos do curso de graduação, mesmo período em que empreendeu suas primeiras pesquisas sociológicas - sob orientação de Si-

* Universidade Estadual Paulista (Unicamp). Departamento de Sociologia.

Rua: Cora Coralina, 100, Barão Geraldo. Cep:13083-896. Campinas - São Paulo - Brasil. fquerido@unicamp.br mão, seu professor preferido, e com o apoio do DIEESE, onde trabalhava como voluntário - destinadas à análise da consciência operária em São Paulo.

Nessas pesquisas, o jovem estudante articulava o interesse militante pelo movimento operário e suas formas de "consciência de classe" com algo do caráter marcadamente empírico que, sob a batuta de Florestan Fernandes que assumira a cadeira de Sociologia I em 1954, tornando-se a figura preponderante das Ciências Sociais uspianas da época -, balizava o padrão científico rigoroso da nascente sociologia paulista. Ao mesmo tempo, e não por acaso, tal modalidade de pesquisa "empírica", tomando como "objeto" o movimento operário-sindical, permitia-lhe "testar" na prática, com os riscos dos mecanicismos implicados nesse tipo de aproximação, por vezes forçada, a perspectiva teórico-metodológica que então condicionava sua interpretação do marxismo, ancorada nas concepções do Lukács de História e Consciência de Classe e, em chave mais sociológica, por assim dizer, de Lucien Goldmann.

Foi exatamente a adesão entusiasta a essa leitura do marxismo - potencializada, po- 
rém, pela oportunidade de estudar com o próprio Goldmann, à qual se acrescentava tanto a paixão pela outrora "capital das revoluções" quanto a "filiação" francesa da USP de então - que impeliu Löwy a tomar o rumo de Paris a fim de lá fazer o doutorado, sob a orientação do sociólogo romeno, acerca do itinerário político e intelectual do jovem Marx em sua caminhada em direção ao que se entenderia por "marxismo", tema de predileção, como se sabe, tanto de Lukács quanto de Goldmann. A ida para a França em 1961 o impediria, assim, de participar do processo de formação do CESIT (Centro de Sociologia Industrial e do Trabalho) no ano seguinte, sob liderança de Florestan Fernandes e de sua equipe de assistentes na Cadeira I, mas do qual também faria parte seu ex-professor Azis Simão (vinculado à Cadeira II), dentre muitos outros.

Pois bem: à luz dessas premissas relacionadas à trajetória do autor, o objetivo deste artigo é analisar o processo de formação intelectual de Michael Löwy, de sua juventude paulistana até o seu retorno definitivo a Paris no final da década de 1960 e início da seguinte, quando consolidará a sua interpretação lukacsiana e goldmanniana do marxismo - como se pode ver, por exemplo, em sua tese sobre a evolução política do jovem Lukács (Löwy, 1997), por ele $\stackrel{\infty}{*}$ próprio descrita como uma "análise lukacsia‥ na da obra de Lukács". Mais especificamente, $\underset{8}{*}$ busca-se investigar as linhas de força (em suas continuidades e descontinuidades) que marcaram o itinerário intelectual de Löwy desde suas primeiras pesquisas sociológicas no Brasil (sobre o movimento operário) até seus estudos mais teóricos - realizados no âmbito de uma "sociologia" marxista (goldmanniana) dos "intelectuais revolucionários" - sobre as obras dos jovens Marx e Lukács, estudos nos quais analisa as motivações ético-políticas que estariam na raiz da adesão de muitos intelectuais "tradicionais" às visões de mundo inspiradas no marxismo. Trata-se, portanto, deve-se ressaltar, do período que antecede a "virada benjaminiana” pela qual passaria Löwy a partir do final da década de 1970, quando a redescoberta das reflexões do crítico alemão impulsionará uma ampliação significativa, tanto de seu horizonte teórico (ainda marxista, mas cada vez mais heterodoxo), quanto de suas preocupações e interesses temáticos. ${ }^{1}$

\section{JUDEU, AUSTRÍACO-ALEMÃO E BRASILEIRO}

Filho de pais judeus austríacos, Félix Michael Löwy nasceu em São Paulo, em 1938. Assim como os de seu velho amigo Roberto Schwarz, os pais de Félix Michael - que, além de judeus, também eram politicamente à esquerda - deixaram Viena, ainda em 1934, em razão das ameaças simultâneas, embora diferentes, representadas tanto pelo desemprego quanto pela ascensão nazista. Mas, enquanto Schwarz, depois de uma tentativa abortada dos pais de se mudarem pra Argentina, nasceu ainda na Áustria, sendo trazido para o Brasil com alguns poucos meses de vida, em 1938, Félix Michael veio ao mundo formalmente brasileiro, nascido em terra brasilis, quando seus pais por aqui já viviam por quase quatro anos. Até os cinco anos de idade, o alemão idioma familiar - era a única língua manejada pelo menino, cindido pela tripla identidade de austríaco, judeu e brasileiro, o que revelava também, por outro lado, as dificuldades nada desprezíveis enfrentadas pela família em sua busca pela aclimatação brasileira. Seria somente na escola, no convívio com os colegas, que Michael Löwy (como preferiria ser chamado) lograria, de fato, aprender o português, adaptando-se à "muito boa" educação que então - naqueles idos dos anos 1940 e início dos 1950, quando a clientela era restrita - se recebia no ensino público de São Paulo, como ele próprio, diversas vezes, reconheceu.

Na adolescência, já com inclinações in${ }^{1}$ A propósito das implicações da redescoberta de Benja-
min na obra e na trajetória intelectual de Michael Löwy,
em chave comparativa com outro benjaminiano tardio,
Daniel Bensaïd, ver Querido (2016b). 
telectuais e políticas à esquerda, encontrou, no irmão, um "sionista de esquerda" (numa época em que isso ainda era possível), uma espécie de primeiro tutor espiritual, responsável por lhe apresentar o marxismo e o socialismo, função que logo seria interrompida com de sua partida para Israel, em 1954, não sem antes indicar um substituto de peso, Paul Singer, outro judeu austríaco que, após flertar com o sionismo (chegando a participar do movimento socialista-sionista "Liberdade"), estabelecera-se como militante de esquerda, de perspectiva luxemburguista, vindo a inspirar, de modo decisivo, os caminhos tomados pelo jovem Löwy. Ao lado de Singer, que chegara a militar na esquerda do PSB, Löwy - que já era socialista e surrealista convicto - participou da fundação da pequena Liga Socialista Independente (LSI), organização da qual também fizeram parte Maurício Tragtenberg, Luiz Alberto Moniz Bandeira, dentre outros, além do outrora trotskista Hermínio Sachetta, um dos líderes (ou o líder) do grupo que se reunia numa minúscula sala da Avenida Brigadeiro Luís Antônio, em São Paulo, cujo único adorno era um retrato de Rosa Luxemburgo. No jornal da Liga, Ação Socialista, Löwy escreveu seus primeiros artigos políticos, em 1957-1958, assinados com os pseudônimos Antônio I. Martinez (operário anarquista assassinado pela polícia durante as greves de 1917, cuja história conhecia por intermédio de Edgard Leuenroth), depois abandonado, e Carlos Rossi, alcunha com a qual seguiria rubricando alguns dos seus textos mais políticos, na França - como os que ele redigia para a revista da LCR, Critique Communiste, de cujo comitê de redação fez parte por algum tempo.

Foi também junto com Paul Singer, ao lado de muitos outros militantes - como os irmãos Eder e Emir Sader, Eric Sachs, Theotônio dos Santos, Ruy Mauro Marini, Renato Caldas (Sachetta se recusou a participar) -, que Löwy tomou parte na fundação da Organização Marxista Revolucionária Política Operária (OMR-POLOP) em Jundiaí, em 1961, acontecimento por ele qualificado como a "ati- vidade política mais importante da minha juventude no Brasil". ${ }^{2}$ A despeito das limitações evidentes, a começar pela pouca penetração nos meios operários, a POLOP representou um contraponto político-intelectual importante às teses hegemônicas na esquerda brasileira, propaladas pelo PCB, defendendo - às vezes de modo pouco dialético - o caráter necessário e imediatamente socialista da revolução brasileira, no que coincidia parcialmente com as formulações que, desde Mario Pedrosa e a Liga Comunista nos anos 1930, eram sustentadas pelos trotskistas brasileiros (Mattos, 2002).

\section{DO SOCIALISMO À SOCIOLOGIA: o movimento operário em questão}

Socialista convicto desde os 14 ou 15 anos, mesma época em que conheceu, numa colônia de férias judaica, em Campos do Jordão, o também jovem judeu socialista Roberto Schwarz (a afinidade entre eles se revelando de forma imediata), Löwy não passou por grandes dilemas no momento da escolha do curso de graduação a que gostaria de se dedicar, escolha, aliás, que se adequava às possibilidades materiais da família, imigrante de classe média, qual seja, o de Ciências Sociais na Faculdade de Filosofia da USP, a qual recebia, naquele momento, um contingente bastante expressivo de jovens saídos de famílias de emigrados, tal como o dueto Löwy-Schwarz, colegas de classe. Para um socialista, acreditava Löwy, na sua ingenuidade juvenil, nada melhor do que as Ciências Sociais, em particular a mais ampla, a mais dominante e a mais à esquerda entre elas, isto é, a sociologia, cujo grau de institucionalização era bastante superior àquele da antropologia e (ou) da ciência política, assim como das outras ciências ditas humanas. ${ }^{3}$ ${ }^{2}$ Os trechos citados entre aspas, mas não identificados, se
referem, salvo indicação em contrário, a entrevistas (ainda
inéditas) do autor com Michael Löwy, realizadas em 2014,
em Paris (França).
${ }^{3}$ Cf., a propósito, Miceli (1989), Blanco e Jackson (2014).
Para uma visão menos focada no aspecto institucional, cf.
Ortiz (1990). 
Desconfiado do "ecletismo" científico, ${ }^{4}$ bem como do "descomprometimento" político da grande estrela da sociologia paulistana daquele momento, Florestan Fernandes -pecados imperdoáveis aos olhos do jovem militante -, Löwy não nutria o mesmo entusiasmo de muitos de seus colegas pelo ambiente acadêmico da USP de então. Mais do que os admirados (não mais que isso) Antonio Candido, Paula Beiguelman, Octávio Ianni e, sobretudo, Fernando Henrique Cardoso, jovem e brilhante professor, ademais de politicamente à esquerda e ligeiramente marxista, seria o mais discreto e improvável Azis Simão, expoente uspiano da sociologia do movimento operário, aquele que faria as vezes de principal mestre acadêmico do jovem Michael Löwy - o qual não rivalizava, todavia, com o papel político-intelectual preponderante exercido por Paul Singer, com quem, diria Löwy, num evidente exagero provocativo, ele teria aprendido muito mais do que em todo o curso de Ciências Sociais.

Sob a orientação de Azis Simão, tio de seus amigos e camaradas de organização política, Eder e Emir Sader, por ele recrutados para a LSI, Michael Löwy realizou suas primeiras pesquisas sociológicas nos últimos anos de graduação - uma espécie de Iniciação Científica, não por acaso ainda precária, na qual alme$\infty$ java perscrutar nada menos do que a consciênN . cia de classe dos operários metalúrgicos de São dos delegados do congresso do Sindicato dos Metalúrgicos ao questionário elaborado pelo jovem sociólogo, através do DIEESE, ${ }^{5}$ onde tra-

. ${ }^{4}$ Sobre o "ecletismo" de Florestan Fernandes, numa visão ๓ं bem mais favorável, cf. Cohn (1987). Cf. também Bastos $\infty$ (1998).

por iniciativa de alguns militantes sindicais, preocupa-

ธิ dos, num contexto de alta inflacionária, com a produção

de dados sobre custo de vida e cesta básica, mercado de

trabalho, greves, desemprego etc., a fim de amparar, com

๙ conhecimento ("técnico") de causa, suas campanhas. Des-

. de sua criação, o DIEESE recebeu o apoio de importantes

I sociólogos paulistas que trabalhavam ou se interessavam

J pelas questões relacionadas ao trabalho, tais como Flores-

tan Fernandes e Azis Simão. Mais ainda: o primeiro diretor

técnico da entidade foi o sociólogo José Albertino Rodri-

gues, autor do livro Sindicalismo e desenvolvimento no

Brasil, publicado em 1968. Sobre as pesquisas desenvol- balhava como voluntário, em que constavam desde perguntas sobre a origem social e a função do sindicato, até, e principalmente, sobre os níveis de consciência "política" de classe dos trabalhadores. Para o jovem "luxemburguista" e simpático aos trotskistas - cioso, portanto, da "independência de classe" - apenas os trabalhadores identificados com os comunistas, os anarquistas ou, no máximo, com os socialistas, detinham algum nível de consciência política de classe, condição da qual se encontravam subtraídos os que se diziam favoráveis aos trabalhistas. À época, a pesquisa no âmbito da sociologia do movimento operário se coadunava, ademais, com a militância do jovem Löwy na União dos Estudantes, mais precisamente, no Departamento de União Operário-Estudantil, do qual fora um dos principais responsáveis pela criação. Como tal, participava, como representante estudantil, das reuniões do Pacto de Unidade Intersindical - hegemonizada pela esquerda sindical sob a influência do PCB, mas dotada de certa abertura política.

Uma primeira versão do artigo com os resultados da pesquisa - premiada pelo recém-criado Centro de Pesquisa dos Estudantes de Ciências Sociais ${ }^{6}$ - seria publicada em 1962, com o título "Opiniões e atitudes de dirigentes sindicais metalúrgicos", na importante Revista Brasileira de Estudos Políticos (MG), periódico que, ao lado da Brasiliense (SP), constituía um dos principais veículos de divulgação das reflexões e pesquisas dos professores e, em menor escala, dos estudantes da USP. ${ }^{7}$ Mais tarde, retrabalhando de modo mais sofisticado o mesmo material, Michael Löwy publicaria uma nova versão - traduzida neste Dossiê pela primeira vez em português - do artigo nos vidas pelo DIEESE, ver Mendonça (2002) e Chaia (1992).

${ }^{6}$ Em segundo lugar ficou Roberto Schwarz, com um estudo sociológico sobre o polo aquático!

7 O próprio Löwy publicou seus três primeiros artigos “acadêmicos” na Revista Brasiliense - em 1960 e 1961, o primeiro sobre "a questão agrária no Brasil" e o segundo sobre o "homem e [a] sociedade na obra do jovem Marx" - e na Revista Brasileira de Estudos Políticos, no caso do texto mencionado sobre a consciência de classe dos dirigentes sindicais. 
Cahiers Internationaux de Sociologie, na França, em 1970, ou seja, já num momento em que seu pensamento, sempre no interior do marxismo, encontrava-se, por assim dizer, em estágio bem mais aprimorado, especialmente se comparado àquele da época em que era estudante de graduação.

\section{ENTRE O MARXISMO ACADÊMI- CO E O HUMANISMO REVOLU- CIONÁRIO}

Nos dois últimos anos de graduação, 1959 e 1960, Michael Löwy participou, como um dos estudantes convidados - ao lado de Roberto Schwarz e Bento Prado Jr., dentre outros -, do chamado "Seminário d'O Capital", grupo (interdisciplinar) de estudos da obra máxima de Marx, liderado por José Arthur Gianotti e Fernando Henrique Cardoso, do qual sairiam algumas das mais destacadas figuras da intelectualidade brasileira da segunda metade do século XX, tais como, além dos dois mencionados, o historiador Fernando Novais, o sociólogo Octávio Ianni, outro dos discípulos de Florestan em processo de radicalização intelectual e política, sem falar, é claro, no economista Paul Singer, que, assim como Löwy e Schwarz, tinha a imensa vantagem de ter o alemão como língua materna.

Diferentemente de Roberto Schwarz para quem o Seminário, a despeito das limitações do momento, inaugurou (ou desenvolveu em nova direção) uma "intuição nova sobre o Brasil”, entre cujos frutos encontrar-se-iam, precisamente, as teses de doutorado produzidas por seus ex-membros -, Michael Löwy tende a subvalorizar a importância da experiência não apenas em sua própria trajetória, o que seria de se esperar, já que ele próprio não seguiu o mesmo caminho de seus pares que permaneceram no país, mas também num sentido mais geral, não vendo nela senão o que aparentemente foi: um grupo de estudos sobre $O \mathrm{Ca}$ pital que, embora não se guiasse inteiramente pela órbita acadêmica, não tinha pretensão alguma de reinterpretar o Brasil ou algo do tipo. Como diria muito recentemente em 2014, "tratava-se antes de tudo [...] de um trabalho de destrinchar o texto, analisar a construção do texto, a estrutura, seguindo muito o tal método filosófico francês de 'explicação do texto' que havia sido importado pelo Gianotti”. Enfim, nada mais do que um "estudo d'O Capital, sem muita relação com o Brasil”. E, sem levar em consideração as consequências imprevistas (os "acasos objetivos", como diria seu mestre André Breton) que essa leitura "acadêmica" de Marx poderia gerar num ambiente tal como o que era vivido à época, consequências que se concretizariam nas diversas teses (sobre o Brasil!) produzidas por seus ex-membros, Löwy afirma: “francamente, eu não me lembro de discussões sobre o Brasil, salvo antes ou depois - na parte mais informal - de começar os debates propriamente ditos sobre o texto. E havia um clima de desprezo pelo marxismo carioca, desde os integrantes do ISEB (que não eram marxistas declarados) até o pessoal do Partidão".

Ora, talvez tenha sido esse "desprezo" pelo "marxismo carioca", por certo bastante provinciano, que teria permitido depois a alguns deles desenvolver uma interpretação relativamente original da formação histórico-social do Brasil, do passado colonial ao capitalismo "subdesenvolvido" e (ou) "dependente" do século XX. Tal originalidade é ressaltada quando contrastada com aquelas interpretações oriundas da esquerda intelectual e política dominante à época. Talvez seu amigo Roberto Schwarz tenha sido exatamente a expressão mais avançada - porque, e não apesar de sua transição para a crítica literária e o ensaísmo, conforme hipótese defendida em outro local (Querido, 2017) - dessa "nova" interpretação do Brasil. Ele foi responsável por uma releitura dialeticamente mais sofisticada, por assim dizer, da articulação subordinada externa do país com os imperativos da ordem capitalista global da qual nascemos como entreposto comercial (como já nos ensinara Caio Prado Jr., 
espécie de precursor dessa "linhagem" intelectual), assim como das consequências internas que, assim sobredeterminadas, concorriam para o bloqueio político, social e econômico das estratégias de superação do "atraso", fundadas na mesma lógica da modernização com a qual era preciso romper.

Michael Löwy estava muito mais interessado, naquele momento, na obra dos recém-descobertos Goldmann (1952) e - quando se publica a edição francesa de História e Consciência de Classe - Lukács (2003), autores através dos quais ele se conectava a uma linhagem "humanista" e "historicista", então ainda hegemônica no marxismo francês e ocidental, tanto mais se pensarmos na inescapável figura, na época, de Jean-Paul Sartre, cuja Crítica da razão dialética (Sartre, 1960) se fez presente discretamente no Seminário, contribuindo, ao lado de Lukács, para a demarcação da feição "marxista" da tese de doutorado (tal qual metodologicamente é expressa na introdução) de Cardoso (1962, p. 9-34).

Daí a tendência, em Löwy, a certo alheamento "universalista", digamos assim, em relação à atmosfera de radicalização política que, bem ou mal, envolvia o chamado ciclo nacional-desenvolvimentista, em especial a partir da virada para os anos 1960. Retrospectivaœ mente, por exemplo, Löwy sustenta que "não . havia”, no final da década de 1950, "um clima

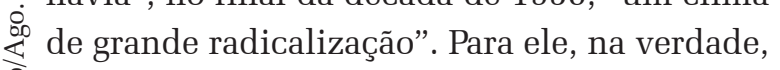
"o clima era bem tíbio", já que, afora o PCB então a força hegemônica na esquerda e que passara por um giro à direita em 1958, com a chamada "Declaração de Março" -, bem como seus aliados de ocasião, nacional-desenvolvimentistas, "não havia uma grande efervescêni cia de esquerda”. Inexistiam, ademais, organizações políticas alternativas (como os trotskistas ou os "luxemburguistas" da LSI, POLOP), capazes de impulsionar um processo efetivo de radicalização política.

Tal percepção pode ser compreendida, mais do que pelas tomadas de posição do próprio Löwy - às quais se ajusta a sua rememo- ração retrospectiva -, através da análise das especificidades de São Paulo nos anos 1950, quando contrastadas, por exemplo, com as do Rio de Janeiro. Diferentemente da então capital federal, epicentro da vaga nacional-popular, a cidade de São Paulo fora palco, naquele momento, de experimentos científicos e artísticos que atinavam com uma dimensão moderna, de corte mais "universalista", no sentido de que se pretendiam em linha com a onda internacional - e isso, no contexto de uma modernização econômica, social e política da cidade em pleno processo de metropolização (Arruda, 2011, p.52). Exemplos significativos dessa nova sociabilidade "moderna" em gestação foram o concretismo e, no que aqui nos interessa mais, a Faculdade de Filosofia da Rua Maria Antônia, em particular na figura de Florestan Fernandes, responsável por uma concepção definida da universidade e da ciência (sociologia). Em ambos os casos, o que estava em questão era a tentativa de se colocar à altura da arte e (ou) da ciência vigentes em países modernamente "desenvolvidos".

Para Florestan Fernandes, por exemplo, a fim de se tornar uma ciência efetivamente "moderna”, tal qual a dos países com tradição histórica na disciplina, a sociologia brasileira deveria constituir-se em torno de um conjunto de instituições, valores e uma linguagem específicas. Tratava-se, na ótica de Fernandes, de se construírem as condições para a necessária ruptura com as formas "tradicionais" de pensamento social, cujo apreço pelo ensaísmo de corte literário mal esconderia um vínculo orgânico com uma "concepção estamental de mundo”, considerada como obstáculo ao pleno florescimento da ordem competitiva entre nós. Em suas próprias palavras: “O nosso padrão de ‘vida literária' foi moldado numa sociedade senhorial e o escritor passou a ver-se, como e enquanto escritor, à luz de uma concepção estamental de mundo.” (Fernandes, 1963, p. 230). Daí o isolamento da Faculdade "moderna" diante de uma realidade ainda a ser "modernizada”, tarefa para a qual a própria sociologia, 
se bem ancorada cientificamente, poderia contribuir. Como afirma Cardoso, até meados do fim da década de 1950, "nós vivíamos numa ilha intelectual” (1988, p. 30).

Em meio a esse ambiente "moderno", aparentemente apartado dos dilemas da nação ainda à procura da modernidade, não surpreende que Michael Löwy tenha optado por fazer o doutorado em Paris, a então capital do marxismo, sob a orientação de Lucien Goldmann, acerca de um tema que, ao longo da década de 1950, isto é, antes mesmo das interpelações althusserianas em Pour Marx (1961-65), ${ }^{8}$ havia se tornado objeto de grande interesse na Europa, a saber: o jovem Marx. Um tema, portanto, segundo ele, cuja escolha não teve qualquer relação com o Seminário d'O Capital. Bem ao contrário, a se considerar que o interesse quase que exclusivo desse seminário era pela obra máxima de Marx, do "velho" Marx: "não sei se deliberadamente, mas tratava-se de uma opção contrária ao espírito, aos interesses, digamos, do seminário".

Apoiando-se metodologicamente na "sociologia da cultura" de Lucien Goldmann, espécie de repaginação sociológica do historicismo lukacsiano, Löwy analisou, entre 1961 e 1964, a evolução do itinerário político e intelectual do jovem Marx, desde suas primeiras intervenções filosóficas no início dos anos 1940 até a elaboração - que se deve à descoberta do movimento operário francês tanto quanto, se não mais, do que às leituras e (ou) releituras então realizados pelo jovem filósofo comunista - do que, depois, se convencionaria denominar marxismo. Para Löwy, como mostraria na tese depois publicada em livro, com o título A teoria da revolução no jovem Marx, apenas em 1845, com as conhecidas "Teses sobre Feuerbach", que Marx lograria superar as antinomias que ainda rondavam suas reflexões, entre o "idealismo" hegeliano e o "materialismo" feuerbachiano, na direção de

${ }^{8}$ Cf. Althusser (2005). Alguns anos mais tarde, Löwy (1970b) se dedicou à leitura althusseriana apresentada nos ensaios (do próprio Althusser, assim como dos seus discípulos) compilados em Lire le Capital, um ensaio crítico intitulado "L'humanisme historiciste de Marx ou relire Le Capital”. uma concepção da práxis - como expressão do ponto de vista do proletariado - tomada como categoria fundamental para a compreensão da "circularidade dialética" entre a objetividade que se impõe como espaço dos possíveis para a prática social e a subjetividade que, embora remeta a condições já pressupostas, nelas interfere ativamente, modificando-as e, assim, transformando a si mesma.

Filosoficamente fundada em Lukács, tal leitura historicista da "gênese" do marxismo se articulava, de modo relativamente coerente, com o pendor militante "luxemburguista" que Michael Löwy trouxera do Brasil, o qual se exprimira na tese por meio da ênfase na práxis como a categoria-chave para a superação do dilema entre objetivismo e subjetivismo, ênfase entre cujos desdobramentos políticos se encontrava a ideia, central em Rosa Luxemburgo, de que a emancipação deve necessariamente significar a autoemancipação do proletariado, "classe universal" porque detentora de uma perspectiva capaz de apreender dialeticamente a totalidade. De onde advém a tese defendida por Löwy e parcialmente contestada por Goldmann - tanto por ocasião da defesa pública quanto em entrevista concedida alguns anos depois - de que o marxismo apenas se constitui como tal, na obra do jovem Marx, quando ele chega à formulação de uma autêntica e original "teoria da revolução proletária".

\section{DE SÃO PAULO A PARIS, A "CA- PITAL DAS REVOLUÇÕES”: um intelectual à europeia}

Em Paris, a partir de 1961, Michael Löwy entrou, quase de imediato, numa das correntes da esquerda do Partido Socialista Unificado (PSU), organização da qual também fazia parte Lucien Goldmann, embora numa de suas tendências mais "moderadas". Na "capital das revoluções”, com a qual o jovem francófono sonhava desde a adolescência paulistana, fascinado que era pelo surrealismo e pela cultura 
francesa de uma forma geral, Löwy começou a se aproximar, agora de modo mais sólido, de mais uma das tendências da esquerda revolucionária que encontrara na França o seu habitat "natural": o trotskismo. No PSU, entre 1961 e 1964, militou na tendência "Socialismo Revolucionário”, então secreta ou discretamente dirigida por Michel Lequenne, personagem histórico do trotskismo francês que, à época, estava rompido com a IV Internacional, mas para a qual não demoraria a retornar. Löwy o reencontraria, anos depois, a partir da virada para os anos 1970, na mesma organização, agora declaradamente trotskista, a Liga Comunista Revolucionária (LCR), conduzida pelos jovens "soixante-huitards" Alain Krivine, Daniel Bensaïd e Henri Weber, depois acompanhados da figura mais ilustre entre os "velhos" trotskistas, o economista belga Ernest Mandel.

Com a entrada na LCR, Löwy finalmente aderia ao internacionalismo trotskista, em especial à sua vertente mais "libertária", embora mesclada a um ultraleninismo não menos imponente, vertente gestada nas revoltas de março a junho de 1968 e liderada por jovens politicamente autoconfiantes o suficiente para dispensar, ao menos num primeiro momento, a tutela dos notáveis, até então tidos como os autênticos guardiões do templo em $\infty$ ameaça constante. Foi com seu amigo Emir iิ Sader, exilado em Paris e assistente de Nicos $\stackrel{80}{<}$ Pou Poulantzas no recém-inaugurado Centro EXperimental de Vincennes (futura Universidade Paris VIII, mais tarde realocada em Saint-Denis), que Löwy decidiu, já de retorno a Paris - após passagens por Israel (1964-68) e Mani. chester (1969), lugares onde trabalhou como ¿ professor universitário -, adentrar nas fileiras iे da IV Internacional. Mas, enquanto Sader se

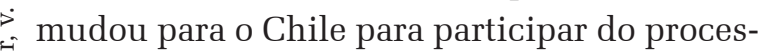
so que culminaria na eleição de Salvador Allende e, mais tarde, no golpe militar liderado fi por Augusto Pinochet, Löwy permaneceu na França, aderindo à LCR e substituindo o amigo na assistência a Poulantzas, cargo no qual ficaria até 1977 , quando seria admitido pelo
Centre Nationale de la Recherche Scientifique (CNRS). ${ }^{9}$

Entretempos, na primeira metade da década de 1970, Löwy fez sua segunda tese de doutorado (doctorat d'État), dessa vez sobre a "evolução política" do jovem Lukács, da juventude romântica ao "realismo revolucionário" de História e Consciência de Classe (HCC) (Lukács, 2003), antes da "reconciliação com a realidade" stalinista, que teria sido promovida pelo filosofo húngaro a partir do final da década de 1920. Löwy arrematava, então, dedicando-se ao itinerário que teria resultado na expressão mais avançada do marxismo (aquele exposto em HCC, mais tarde desdobrado por vários outros autores), a sua própria concepção lukacsiana-goldmanniana da teoria social inaugurada por Marx, que seria parcialmente superada apenas com a redescoberta da obra de Walter Benjamin por volta de 1979.

Na Europa, Michael Löwy estabeleceu-se assim, recusando o papel subalterno comumente destinado ao intelectual oriundo da periferia do mundo, qual seja: aquele dedicado e restrito à interpretação dos dilemas de seu país ou região - a América Latina, por exemplo. Löwy por lá se firmou através do estudo de temas e de interesses como os de qualquer intelectual europeu, como, por exemplo, as obras de Marx, Lukács ou Goldmann, ou a pesquisa sobre sociologia do conhecimento (em que acrescenta a inspiração mannheimniana), pesquisa com a qual, aliás, seria admitido como pesquisador no CNRS. Conforme observa Marcelo Ridenti, num ótimo texto-homenagem consagrado ao autor, embora jamais tenha renegado o Brasil ou a América Latina - muitíssimo pelo contrário, como se veria nos anos 1990 e 2000, com o tournant latino-americano pelo qual passaria sua trajetória -, Löwy consolidou-se, na França, como um "intelectual europeu", entusiasta das "utopias socialistas internacionalistas". Nas palavras de Ridenti:

Filho de imigrantes judeus, tendo aprendido alemão em casa como língua materna, vivendo em um meio

${ }^{9}$ Sobre a relação com Poulantzas, Löwy (2014). 
repleto de outros imigrantes e seus descendentes, cursando o ensino superior nos padrões de excelência europeus do Curso de Ciências Sociais da USP de então, com a mente e o coração conquistados pelas utopias socialistas internacionalistas, é sintomático que sua obra nunca tenha se debruçado mais detidamente sobre a sociedade brasileira, nem sobre qualquer intelectual conterrâneo, o que se explica também por sua recusa em ocupar o lugar considerado subalterno que geralmente se concede, na França, ao estrangeiro, de quem se espera apenas que estude seu país ou região de origem (2007, p. 170-171).

\section{EXCURSO BENJAMINIANO: o que foi, à luz do poderia ter sido}

Ao não permanecer em São Paulo, optando por tentar a sorte no (ainda) centro intelectual do mundo, mais precisamente, na autêntica pátria dos intelectuais, a França, país por onde passaram quase todos os grandes dos séculos XIX e XX, Michael Löwy viu interrompida, assim, sua breve passagem pela "sociologia do movimento operário" que aprendera com Azis Simão. ${ }^{10}$ Tal sociologia, através do próprio Simão, bem como do jovem pesquisador e ex-militante trotskista (tendo passado pelo PSR e, após a dissolução deste, pelo POR) Leôncio Martins Rodrigues, estaria muito bem representada no âmbito do Centro de Estudos de Sociologia Industrial e do Trabalho (CESIT), criado em 1962 em torno da Cadeira I de Sociologia da USP, graças aos esforços de Florestan Fernandes e de Fernando Henrique Cardoso, esse último não hesitando em lançar mão dos seus contatos com o mundo empresarial a fim de angariar os recursos necessários à empreitada, que também acabou sendo financiada pelo governo estadual de Carvalho Pinto (Braga, 2012, p. 44-50; Romão, 2006).

${ }^{10}$ Mais tarde, na França, Löwy estabeleceria estreitas relações com o historiador do movimento operário Georges Haupt, judeu de origem romena, como Goldmann. Mas o foco de sua interlocução com Haupt eram as análises marxistas da questão nacional, tema de livro por eles publicado, junto com Claudie Weill, em 1974 (Haupt; Löwy; Weill, 1974).
Apoiando-se em três grandes eixos de pesquisa que definiam a modernização capitalista periférica no país - a mentalidade do empresariado, o papel do Estado no desenvolvimento e, por fim, as características da mobilização da força de trabalho nesse processo -, o CESIT demarcou a entrada em cena da sociologia paulista nos debates sobre os entraves (os "obstáculos estruturais", na linguagem de Fernandes) ao desenvolvimento do Brasil, em oposição relativa às abordagens nacionalistas e (ou) populistas hegemônicas. Em coerência com a sociologia "uspiana” da modernização, Leôncio Martins Rodrigues foi quem mais se dedicou, no CESIT, ao estudo da consolidação do fordismo periférico, como observa Braga (2012, p. 48-65), analisando o comportamento do movimento sindical em uma realidade social como a brasileira, que seria historicamente sobredeterminada pela permanência de aspectos característicos do "atraso" pré-moderno, por assim dizer, atraso cujo impacto negativo na conformação do papel dos trabalhadores na "regulação" dos processos de acumulação seria enorme. A conservação de tais aspectos típicos de uma cultura política arcaica era tanto mais ressaltada porque contrastada - como era praxe no horizonte modernizador dos jovens sociólogos da USP até pelo menos 1964 - com aquela vigente nos países desenvolvidos tomados como modelos.

Para Leôncio Martins Rodrigues, tal como está exposto nos três estudos compilados em Conflito industrial e sindicalismo no Brasil (1966), o subdesenvolvimento afetava tanto o tipo de relação da massa dos trabalhadores com o Estado quanto a postura dela no interior das fábricas, a qual passava por uma visão "paternalista" do sindicato, que acabava por bloquear qualquer possibilidade de que o proletariado se erigisse "no centro impulsionador de um processo político de mudança social" para além do consentimento passivo e da correlata manipulação pela liderança populista (Braga, 2012, p. 59; Rodrigues, 1966, p. 209). Por meio de questões não muito diferentes da- 
quelas do estudo do jovem estudante Löwy, ${ }^{11}$ embora num nível bem mais elevado de amplitude e rigor, questões aplicadas aos operários da empresa Willys-Overland, em São Bernardo, Rodrigues sublinhou a percepção majoritariamente assistencialista que, segundo ele, os trabalhadores - em particular os operários semiqualificados e de origem rural - cultivavam do sindicato. Entre a "minoria sindicalizada", apenas $29 \%$ teriam oferecido "respostas classistas', ou seja, respostas que mencionam o sindicato não como entidade assistencial, mas como organização de defesa do proletariado" (Rodrigues, 1966, p. 107-8).

A se considerar a história, em linha benjaminiana, não apenas como o que efetivamente foi, senão também como aquilo que poderia ter sido, seria interessante interrogar como Löwy se posicionaria, se não tivesse decidido viver do outro lado do Atlântico, diante da sociologia "uspiana" da modernização, que ganhara novo impulso com a fundação do CESIT, no contexto dos debates que marcaram o ciclo nacional-desenvolvimentista abortado abruptamente em 1964, não por acaso em seu momento de maior radicalização política (e intelectual). Se aqui ficasse em 1961, talvez Löwy não lograsse - ao preço de um alheamento político pouco provável - se esquivar $\stackrel{\infty}{\sigma}$ de modo tão peremptório da vaga de radicaN lização à esquerda que impactaria os debates $\stackrel{\infty}{\stackrel{\infty}{2}} \mathrm{~s}$ sobre a questão nacional.

Muito embora hegemonizada pelas orientações "nacionalistas", seja do PCB ou do ISEB, tal questão pautava o conjunto da esquerda política e intelectual, já que, de um ळ. modo ou de outro, a compreensão do capitalismo periférico passava pela apreensão da - formação histórica do país no seu entrelaçamento nacional particular entre o moderno e o arcaico. Como Schwarz (1999) argumentaria décadas depois - no que seria uma crítica retrospectiva -, até mesmo entre os próceres do Seminário d'O Capital, que de autênticos "nacionalistas" pouco tinham, o horizonte ${ }^{11}$ Cf. artigo de Michael Löwy nesse dossiê. industrializante e modernizador dava o tom, uma vez que também para eles se tratava de fazer “o país dar certo", e o parâmetro para isso acabava inevitavelmente sendo a modernidade capitalista dos países centrais, à parte a ruptura socialista desejada por alguns - ruptura ela própria, porém, envolta nas particularidades do Brasil. Conforme perguntaria retoricamente o mesmo Schwarz, comentando os resquícios dessa perspectiva na Crítica à razão dualista, de Chico de Oliveira: "Como não seria assim? Num sistema mundial de reprodução das desigualdades, como não disputar uma posição melhor, mais próxima à dos vencedores e menos truncada?" (Schwarz, 2003, p. 20).

\section{UM INTELECTUAL DO MUNDO}

Tanto a obra quanto a trajetória de Michael Löwy expressam, assim, como acompanhamos neste artigo, a condição (tornada vocação) cosmopolita de um intelectual que, seja pelos temas escolhidos, seja pela forma idiossincrática de abordá-los, se estabeleceu como figura singular no espectro do marxismo e do pensamento crítico contemporâneo. Tal cosmopolitismo, uma das marcas dos intelectuais “judeus não judeus” (Deutscher, 1969). do século XX, mas agora sem as intempéries do exílio forçado, tornou possível a Löwy consolidar-se como intelectual europeu de pleno direito, percepção compartilhada mesmo por seus colegas brasileiros. Em entrevista de 2001, por exemplo Cardoso (2006, p. 76) assim se refere ao ex-aluno: "Michael Löwy, que depois virou famoso na Europa”.

O cosmopolitismo internacionalista jamais estremeceu, porém, a fidelidade ao país que acolhera sua família, e no qual vivera suas primeiras experiências políticas e intelectuais: o Brasil. Fidelidade que se intensificaria a partir de meados dos anos 1980, quando a derrocada gradual da ditadura lhe permitiria visita-lo com regularidade. Talvez não por acaso, foi nesse mesmo período que a obra de Löwy 
passou por um giro benjaminiano que, entre outras coisas, o levou a uma espécie de retorno às raízes, com a Europa central de cultura alemã e a América Latina passando ao primeiro plano de seus interesses de pesquisa. Nesse contexto, Löwy passaria a refletir sobre uma condição social - a do intelectual judeu, entre o particularismo utópico-religioso e o cosmopolitismo ético-político - que, em grande medida, guardadas as devidas proporções, era a sua própria, a despeito da ausência, no seu caso, de qualquer relação propriamente religiosa com o judaísmo. Pelo momento histórico em que era realizado, a partir dos anos 1980, não surpreende que o resgate desses intelectuais marginais, outsiders, ganhasse ares de resistência intelectual e política, caixa de ressonância da negatividade em relação ao presente e da utopia projetada para o futuro.

Por isso mesmo, se a primeira fase de sua obra, até meados dos anos 1970, difere daquela que seria elaborada depois, mais ampla e original, ela, de alguma forma, a prenuncia, uma vez que estava orientada, desde muito cedo, pela vocação cosmopolita do intelectual politicamente internacionalista e intelectualmente desenraizado. ${ }^{12}$ Afinal de contas, como se argumentou aqui, foi na São Paulo dos anos 1950, cidade em plena efervescência moderna, mas de uma modernidade destituída do vínculo orgânico com o nacional-popular, que o jovem Löwy - surrealista e socialista internacionalista - fincou as bases de uma carreira intelectual que, tendo sido completamente exitosa, jamais abdicou da convicção de que é, sim, necessário instigar a imaginação concreta de outro mundo possível, tal como o fez a maior parte dos seus "objetos" de estudo - do passado ou do presente, do centro ou da periferia do mundo capitalista.

Recebido para publicação em 15 de janeiro de 2018 Aceito em 23 de maio de 2018

12 Para uma visão panorâmica da obra de Löwy a partir do final dos anos 1970, isto é, após a virada benjaminiana pela qual passou, Querido (2016a).

\section{REFERÊNCIAS}

ALTHUSSER, L. Pour Marx. Paris: La Découverte, 2005.

ARRUDA, M. A. N. Metrópole e cultura. São Paulo no meio século XX. Bauru: EDUSC, 2001.

BASTOS, E. R. "Florestan Fernandes e a construção das Ciências Sociais". In: MARTINEZ, P. H. (Org.). Florestan ou sentido das coisas. São Paulo: Boitempo, 1998.

BLANCO, A; JACKSON, L. C. Sociologia no espelho. Ensaístas, cientistas sociais e críticos literários no Brasil e na Argentina (1930-1970). São Paulo: Editora 34, 2014.

BRAGA, R. A política do precariado: do populismo à hegemonia lulista. São Paulo: Boitempo, 2012.

CARDOSO, F. H. Capitalismo e escravidão no Brasil meridional. O negro na sociedade escravocrata do Rio Grande do Sul. São Paulo: Difusão Europeia do Livro, 1962.

CARDOSO, F. H. "Entrevista concedida a Elide Rugai Bastos, Fernando Abrucio, Maria Rita Loureiro e José Marcio Rego". In:_Conversas com sociólogos Marcio Rego". In:
brasileiros. São Paulo: Editora 34, 2006. p.67-94.

“Memórias da Maria Antônia”. In: SANTOS, M. C. L. (Örg.) Maria Antônia: uma rua na contramão. São Paulo: Nobel, 1988.

CHAIA, M. W. Intelectuais e sindicalistas: a experiência do Dieese (1955-1990). Ibitinga: Humanidades, 1992.

COHN, G. "Ecletismo bem temperado". In: D'INCAO, M. A. (Org.) O saber militante: ensaios sobre Florestan Fernandes. São Paulo: Paz e Terra, 1987.

DEUTSCHER, I. "Le juif non-croyant". In: sur le problème juif. Paris: Payot, 1969. p. 33-54. Essais

FERNANDES, F. A sociologia numa era de revolução social. São Paulo: Nacional, 1963.

GIANOTTI, J.A. "Entrevista”. In: MONTEIRO, P.; MOURA, F. (Orgs.) Retrato de Grupo - 40 anos do CEBRAP. São Paulo: Cosac Naify, 2009.

GOLDMANN, L. Sciences humaines et philosophie. Paris: PUF, 1952.

HAUPT, G.; LÖWY, M.; WEILL, C. Les marxistes et la question nationale, 1848-1914. Paris: Maspero, 1974.

LÖWY, M. A evolução política de Lukács (1909-1929). [1976]. São Paulo: Cortez, 1997.

.Homem e sociedade na obra do jovem Marx". Revista Brasiliense, São Paulo, n. 40, 1961.

.L'humanisme historiciste de Marx ou relire le capital". L'Homme et lasociété. Paris, n.15, 1970b.

"Nicos Poulantzas tel que jê l'ai connu". Entrevista concedida a Alexis Cukier, Razmig Keucheyane Fabio Mascaro Querido. In: . Contretemps web. 2014. Disponível em:<://www.contretemps.eu/nicospoulantzas-tel-que-je-lai-connu-par-michael-lowy/> . Acesso em: 10 dez. 2017.

. "Notas sobre a questão agrária no Brasil”. Revista Brasiliense, São Paulo, n.31, 1960.

. "Opiniões e atitudes de dirigentes sindicais metalúrgicos". Revista Brasileira de Estudos Políticos, Belo Horizonte, n.13, 1962.

. "Structure de la conscience de classe ouvrière au Brésil". Cahiers internationaux de sociologie, v. XLIX, 1970a.

. A teoria da revolução no jovem Marx. [1970]. São Paulo: Boitempo, 2012. 
LUKÁCS, G. História e consciência de classe. São Paulo: Martins Fontes, 2003.

MATTOS, M. B. Em busca da revolução socialista: a trajetória da POLOP (1961-1967). In: REIS FILHO, D. A.; RIDENTI, M. (Orgs.) História do marxismo no Brasil, v. 5 (Partidos e Organizações dos anos 20 aos 60). Campinas, SP: Unicamp, 2002. p.185-212.

MENDONÇA, S. "A experiência do Dieese em pesquisa e conhecimento". São Paulo em Perspectiva, São Paulo, v.16, n.3, 2002.

MICELI, S. "Condicionantes do desenvolvimento das ciências sociais". In:

São Paulo: Vértice, 1989. História das Ciências Sociais.

ORTIZ, R. "Notas sobre as ciências sociais no Brasil". Novos Estudos CEBRAP, São Paulo, n. 27, 1990.

QUERIDO, F. M. Michael Löwy: marxismo e crítica da modernidade. São Paulo: Boitempo/FAPESP, 2016a.

"Pensamento ao quadrado: Roberto Schwarz e o Brasil". In: $41^{\circ}$ ENCONTRO ANUAL DA ANPOCS. Caxambu-MG, 2017
Resistência intelectual e engajamento político em Michael Löwy e Daniel Bensaïd: afinidades benjaminianas. 2016b. Tese (Doutorado em Sociologia) Instituto de Filosofia e Ciências Humanas, UNICAMP.

RIDENTI, M. "Romântico e errante". In: JINKINGS, I.; PESCHANSKI, J. A. (Orgs.) As utopias de Michael Löwy: reflexões sobre um marxista insubordinado. São Paulo: Boitempo, 2007, p.167-174.

RODRIGUES, L. M. Conflito industrial e sindicalismo no Brasil. São Paulo: Difusão Europeia do Livro, 1966.

ROMÃO, W. Sociologia e política acadêmica nos anos 1960: a experiência do CESIT. São Paulo: Humanitas, 2006.

SARTRE, J. P. Critique de la raison dialectique. Paris: Gallimard, 1960.

SCHWARZ, R. "Um seminário de Marx". In: Sequencias brasileiras: ensaios. São Paulo: Companhia das Letras, 1999. p. 86-105.

Prefácio com perguntas. In: OLIVEIRA, F. Crítica à razão dualista. O ornitorrinco. São Paulo: Boitempo, 2003. p.11-23. 
FROM SÃO PAULO TO PARIS: the young Michael Löwy between socialism and sociology

Fabio Mascaro Querido

Although to be better known for his international trajectory, especially that which began in the late 1960s in France, it was in São Paulo that Michael Löwy began his intellectual itinerary in the second half of the 1950s. The purpose of this article is to analyze the importance of this process of intellectual formation of Löwy, between the late 1950s and the mid - 1970s. The aim is to analyze some of the leading threads of the intellectual trajectory of the author, from his first researches on the labor movement within the sociology of São Paulo until his more theoretical work in France, on the works of Marx, Lukács and other "revolutionary intellectuals".

Keywords: Intellectuals. Sociology. Socialism. Cosmopolitism. Engagement.

\section{DE SÃO PAULO À PARIS: le jeune Michael Löwy entre socialisme et sociologie}

Fabio Mascaro Querido

Bien que plus connu par sa trajectoire internationale brillant, notamment celle qui a commencé à la fin des années 1960 en France, Michael Löwy a fait les premiers pas de son parcours intellectuel à São Paulo dans la seconde moitié des années 1950, lorsqu'il a suivi le cours de Sciences Sociales à la Faculté de Philosophie de l'USP, alors située à la rue Maria Antônia. Le but de cet article est d'analyser l'importance de cette période pour la formation intellectuelle de Löwy, entre la fin des années 1950 et le milieu des années 1970. On cherche à analyser certains des fils conducteurs de cette période de la trajectoire intellectuelle de l'auteur, dès ses premières recherches sur le mouvement ouvrier au sein de la sociologie de São Paulo jusqu'à son travail plus théorique en France sur les œuvres de Marx, Lukacs et d'autres «intellectuels révolutionnaires».

Mots-CLÉs: Intellectuels. Sociologie. Socialisme. Cosmopolitisme. Engagement.

Fabio Mascaro Querido - Doutor em Sociologia. Professor do Departamento e do Programa de PósGraduação em Sociologia da UNICAMP. Autor de Michael Löwy: marxismo e crítica da modernidade (Boitempo Editorial, 2016) e de diversos artigos em revistas nacionais e internacionais. Membro do comitê editorial da Coleção Sociologias Contemporâneas (Editora Alameda) e do Grupo de Pesquisa Teoria Crítica e Sociologia (CNPq). 
